Research Article

\title{
Effects of Size, Section Pattern, and Material on the Tensile Performance of Filled Thin-Walled Tubes
}

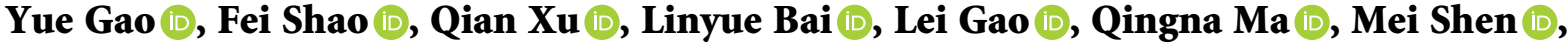 \\ and Xintong Yan $(\mathbb{D}$
}

Field Engineering College, Army Engineering University of PLA, Nanjing 210007, China

Correspondence should be addressed to Fei Shao; shaofei@seu.edu.cn, Qian Xu; 1058427910@qq.com, and Linyue Bai; baily016@sina.cn

Received 27 July 2021; Revised 15 October 2021; Accepted 4 December 2021; Published 18 December 2021

Academic Editor: Ivan Giorgio

Copyright ( $\odot 2021$ Yue Gao et al. This is an open access article distributed under the Creative Commons Attribution License, which permits unrestricted use, distribution, and reproduction in any medium, provided the original work is properly cited.

\begin{abstract}
The tensile performance of ductile tubes can be enhanced by the application of fillers. Research studies on the mechanical performance of filled tensile tubes have mainly focused on experiments and numerical simulations on concrete-filled steel tube (CFST) components, while the effects of factors such as size, section pattern, and material of filled tensile tubes on their performance have rarely been studied. In this research, the effects of size, section pattern, and material on the tensile performance of filled tubes have been evaluated through theoretical studies, simulations, and experiments. The tensile strength reinforcement and deformation weakening coefficients of filled circular thin-walled tubes corresponding to hollow tubes were theoretically deduced, and the influencing factors of the two were parametrically evaluated. Tensile performances of filled tubes with circular and square sections were compared with each other through numerical methods. In the current research, the circular section was optimized and prestressed circular hollow support section was proposed. Tensile fracture tests were performed on circular thin-walled tubes made of six different materials to determine material effects on the tensile performance of these structures. It was also found that metallic materials with good ductility significantly enhanced the tensile performance, fracture toughness, and energy consumption of test components containing prestressed filler.
\end{abstract}

\section{Introduction}

Continuous development of construction industry has put forward higher requirements for engineering structures. Large span, towering, and heavy load are among important development trends of modern engineering structures, which require structures to function under harsh conditions and meet industrialization requirements of construction technology. For example, concrete-filled steel tubes (CFSTs) are taken. Steel tubes restrain concrete during stretching process, making concrete in a state of complex stress, so that strength, plasticity, and toughness of concrete can be greatly improved. Due to the presence of concrete, local buckling of steel tubes can be avoided or delayed, ensuring the full performance of steel tubes [1]. The application scenario of tensioned CFST components in engineering practice is shown in Figure 1.

Research on the mechanical performance of filled tensile tubes has mainly focused on experimental tensile tests and numerical simulations of CFST components, and only a few researchers have performed experimental studies on steel components with flexible fillers. CFST design specifications of Japan, the United States, and Europe (AIJ2008 [2]; AISC2005 [3]; EC4 [4]) consider CFST components under tension to be the same as hollow steel tubes under tension by neglecting concrete effects. According to GB 50936-2014 Technical code for concrete-filled steel tubular structures of China, the tensile strengths of CFST components are considered to be $10 \%$ higher than those of corresponding hollow steel tubes [5].

Some fruitful research works have been conducted around the world on CFST components under tension. Pan et al. [6] performed experimental and theoretical studies on tensile CFST components with three steel tube types, two filled concrete types, and five thicknesses. The obtained results revealed that the longitudinal yield stresses of CFST components were about $10 \%$ higher than those of the 


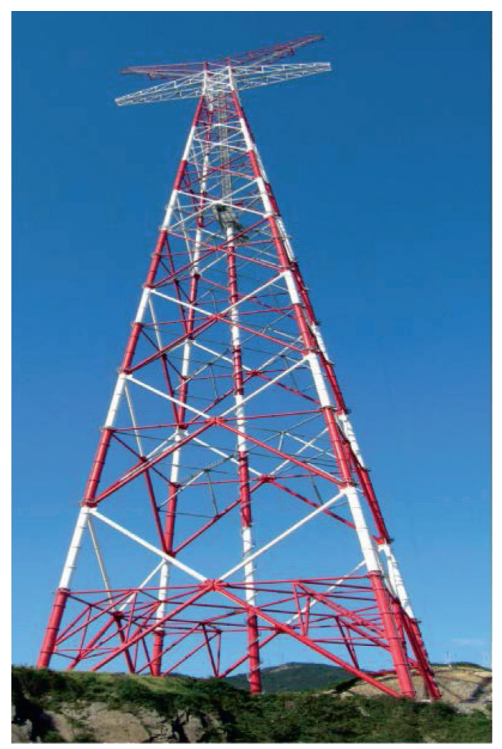

(a)

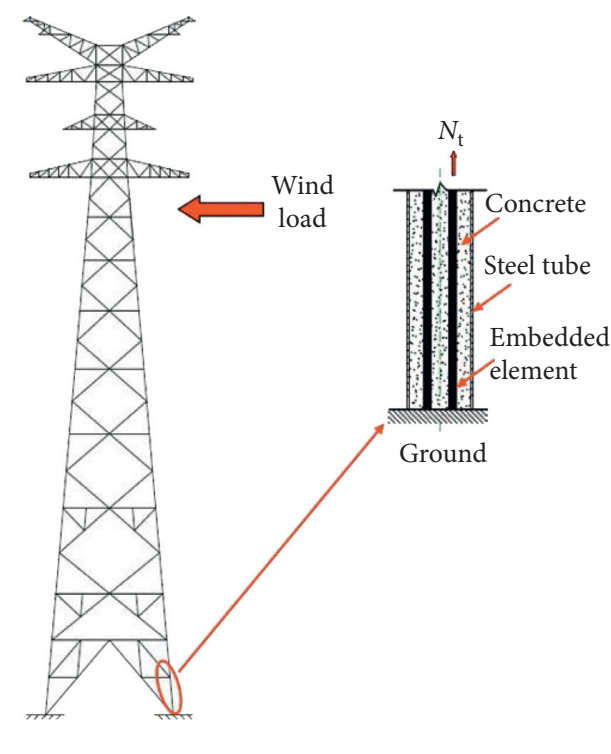

(b)

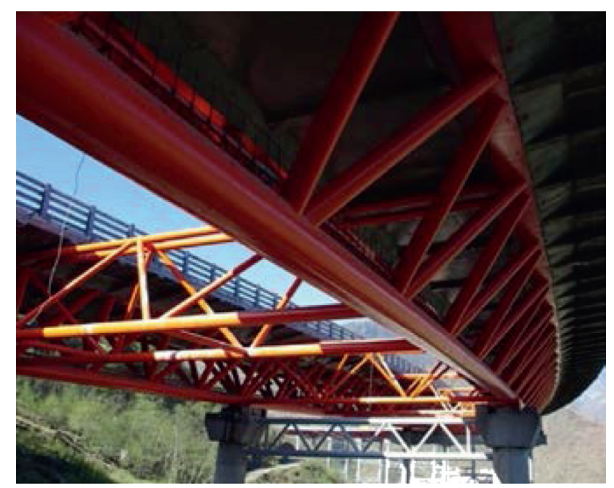

Figure 1: (a) Transmission tower. (b) Tensioned side of the transmission tower under strong wind. (c) Tensioned lower chord of a truss bridge.

corresponding hollow tubes. Han et al. [7-11] experimentally studied the mechanical behaviors of CFST components with specific sizes under tension. CFST components under tension were compared with corresponding hollow tube components, and calculation equations of the tensile strength of CFST components were derived. Experimental and theoretical studies were carried out on concrete-filled stainless steel tubes (CFSSTs), concrete-filled double skin steel tubes (CFDSTs), concrete-encased concrete-filled steel tubes (CECFSTs), angleencased concrete-filled steel tubes (AECFSTs), and square concrete-filled steel tubes (SCFSTs) with specific sizes, involving centripetal tension, eccentric tension, load transfer mechanism, strength, and stiffness analysis models [12-16].

A few research works have been reported on steel components with flexible fillers. Zhu [17] conducted tensile simulations on polyurethane (PU)-filled steel tube (PFST) components. The working principles of composite PFSTs under axial loads were investigated in detail, focusing on steel tube hoop effect on PU. Hang [18] performed numerical simulations on PU-filled double skin steel tube (PFDST) components under axial tension using finite element analysis and derived the equation of ultimate tensile capacity of PFDST components through finite element regression method. Gao et al. [19] conducted tensile fracture tests on 304 stainless steel thin-walled tube (SSTWT) components under different supporting conditions (PU, polytetrafluoroethylene (PTFE), acrylonitrile butadiene styrene (ABS), and Q235 steel) and determined the variations of their ultimate tensile strength, elongation, and fracture energy by the elastic modulus of internal supporting material. The maximum increase in ultimate tensile strength, elongation, and fracture energy was found to be $10.81 \%$, $24.56 \%$, and $35.94 \%$, respectively. Gao et al. [20] studied the strengthening effect of internal support on the tensile strength of thin-walled tube in terms of stress and deformation, deduced the calculation equation of filled tube tensile strength, and conducted tensile tests on the stainless thin-walled tube filled with PTFE. It was found that the average increase in yield force, ultimate bearing capacity, elongation after fracture, and fracture energy was $10.81 \%$, $15.35 \%, 19.33 \%$, and $47.38 \%$, respectively.

The above studies on internal support effect on the tensile mechanical properties of thin-walled tubes were mostly based on experiments and numerical and theoretical studies on specific specimens/models. However, these studies had certain limitations. For example, they considered specific sizes, cross-sectional forms, and materials (as shown in Table 1) and no research has been conducted on the influence law of tube size, cross-sectional form, and tube material.

In this research, the effects of size, section pattern, and material on the tensile performance of filled thin-walled tubes have been investigated by theoretical, experimental, and simulation methods. The tensile strength reinforcement and deformation weakening coefficients of filled circular thin-walled tubes corresponding to hollow tubes were derived theoretically, and the influencing factors of the two were investigated parametrically. Numerical methods were applied to compare filled tensile tubes with circular and square sections. Prestressed circular hollow support section was proposed. Tensile fracture tests were applied on circular thin-walled tubes made of six different materials to determine material effects on the tensile performance of filled circular thin-walled tubes.

\section{Size Effect on Internal Supporting Effect}

The increase in the longitudinal yield stress of steel tubes mainly depended on radius-to-thickness ratio $(\lambda)$, while elastic modulus $\left(E_{\mathrm{in}}\right)$ and Poisson's ratio $\left(\mu_{\mathrm{in}}\right)$ of internal supporting material were also effective. 
TABLE 1: Sizes and filling materials of different components under tension.

\begin{tabular}{|c|c|c|c|c|}
\hline \multirow{2}{*}{ Reference } & \multirow{2}{*}{ Component type } & \multicolumn{2}{|c|}{ Steel tube } & \multirow{2}{*}{ Filler } \\
\hline & & Diameter $(\mathrm{mm})$ & Thickness (mm) & \\
\hline Han et al. [7] & CFST & 140,180 & $3.8,3.85$ & $\begin{array}{l}\text { Self-consolidating C60 concrete steel fiber-reinforced C70 } \\
\text { concrete }\end{array}$ \\
\hline Li et al. $[8]$ & CFST & 140 & $1.98,2.99$ & C60 concrete \\
\hline Han et al. [9] & CFST & 160 & 3.92 & C40 concrete \\
\hline Chen et al. [10] & CFST & 400 & 4,6 & C60 concrete with reinforcing bars or angles \\
\hline $\begin{array}{l}\text { Chen et al. [11] } \\
\text { Han et al. [14] }\end{array}$ & CECFST & 114,76 & $2.6,1.98$ & 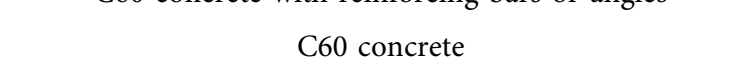 \\
\hline $\mathrm{Xu}$ et al. $[15]$ & AECFST & 400 & 5 & C50 concrete with encased angles \\
\hline Zhu [17] & PFST & 45,48 & 3 & PU \\
\hline Gao et al. [19] & 304 SSTWT & 30.0 & 2.15 & PU, PTFE, ABS, Q235 \\
\hline
\end{tabular}

2.1. Hypotheses and Basic Assumptions. The following basic assumptions were considered in this work:

(1) There were no initial adherence and frictionless contact between the internal support and the thinwalled circular tube; that is, the frictional shear stresses, initial adherence, and chemical bond between the two materials on the tube's behavior were neglectable.

(2) The radial stress gradient of thin-walled circular tubes was ignored for the thinner tube wall. The inner and outer walls of circular tubes were regarded as yielding and then entering plastic state at the same time.

(3) Thin-walled circular tubes undergo elastic and plastic deformations in turn, while internal support only experienced elastic deformation during stretching process.

(4) After thin-walled circular tubes entered plastic stage, the volume invariance principle and the uniform deformation theory were assumed.

(5) Thin-walled circular tubes met the Mises yield criterion and isotropic linear hardening hypothesis.

2.2. Radius-to-Thickness Ratio of CFST. The limits of radiusto-thickness ratio of CFST section in various codes were stipulated as follows.

AIJ2008 [2] in Japan stipulates that the $\left(D_{0} / t\right)$ of CCFST should meet the following condition:

$$
\frac{D_{0}}{t} \leq 1 \cdot 5 \frac{240}{F / 98}
$$

and the $(B / t)$ of SCFST should meet the following condition:

$$
\frac{B}{t} \leq 1 \cdot 5 \frac{74}{\sqrt{F / 98}}
$$

where

$$
F=\min \left(\sigma_{s}, 0 \cdot 7 \sigma_{u}\right)
$$

AISC2005 [3] in the USA stipulates that the $\left(D_{0} / t\right)$ of CCFST should meet the following condition:

$$
\frac{D_{0}}{t} \leq 0 \cdot 15 \frac{E}{\sigma_{s}}
$$

and the $B / t$ of SCFST should meet the following condition:

$$
\frac{B}{t} \leq 2 \cdot 26 \frac{E}{\sigma_{s}},
$$

where $E$ is steel tube elastic modulus and $E=200 \mathrm{GPa} ; D_{0}$ is circular tube external diameter; $B$ is square tube side length; and $t$ is wall thickness.

EC4 [4] in EU stipulates that the $D_{0} / t$ of CCFST should meet the following condition:

$$
\frac{D_{0}}{t} \leq 90 \frac{235}{\sigma_{s}}
$$

and the $B / t$ of SCFST should satisfy the following condition:

$$
\frac{B}{t} \leq 52 \sqrt{\frac{235}{\sigma_{s}}} .
$$

GB 50936-2014 [5] in China stipulates that the $D_{0} / t$ of CCFST should meet the following condition:

$$
\frac{D_{0}}{t} \leq 135 \frac{235}{\sigma_{s}}
$$

and the $B / t$ of SCFST should meet the following condition:

$$
\frac{B}{t} \leq 60 \sqrt{\frac{235}{\sigma_{s}}} .
$$

ACI 318-2 (2002) in the USA [21] and BS5400 in the UK [22] stipulate that the $D_{0} / t$ of CCFST should meet the following condition:

$$
\frac{D_{0}}{t} \leq \sqrt{8 \frac{E}{\sigma_{s}}},
$$

and the $B / t$ of SCFST should meet the following condition:

$$
\frac{B}{t} \leq \sqrt{3 \frac{E}{\sigma_{s}}},
$$

where $E=200$ and $206 \mathrm{GPa}$ for ACI 318-2 (2002) and BS5400, respectively. 
The limits of radius-to-thickness ratio of CFST section could be determined based on the above specifications, but they do not describe the influence of radius-to-thickness ratio on CFST strength. Pan et al. [6] performed axial tension tests on CFST components with five radius-to-thickness ratios and found that the increase in the longitudinal yield stress of steel tubes mainly depended on the content of steel, but not on the grades of concrete and steel. Other research works on the tensile performance of filled components have mainly focused on axial tensile tests or numerical simulations using components with specific sizes, lacking theoretical explorations.

We believe that the increase in longitudinal yield stress of steel tubes mainly depended on radius-to-thickness ratio $(\lambda)$, while elastic modulus $\left(E_{\text {in }}\right)$ and Poisson's ratio $\left(\mu_{\text {in }}\right)$ of internal supporting material were also effective.

\subsection{Reinforcing Mechanism of Internal Supporting Effect.}

The deviatoric stress state of microelement is presented in Figure 2. According to Ref. [23], the expression of the second invariant of deviator stress can be expressed as follows:

$$
\begin{aligned}
J_{2} & =-\left|\begin{array}{cc}
\sigma_{x}-\sigma_{o} & \tau_{x y} \\
\tau_{y x} & \sigma_{y}-\sigma_{o}
\end{array}\right|-\left|\begin{array}{cc}
\sigma_{y}-\sigma_{o} & \tau_{y z} \\
\tau_{z y} & \sigma_{z}-\sigma_{o}
\end{array}\right|-\left|\begin{array}{cc}
\sigma_{z}-\sigma_{o} & \tau_{z x} \\
\tau_{x z} & \sigma_{x}-\sigma_{o}
\end{array}\right| \\
& =\frac{1}{6}\left[\left(\sigma_{x}-\sigma_{y}\right)^{2}+\left(\sigma_{y}-\sigma_{z}\right)^{2}+\left(\sigma_{z}-\sigma_{x}\right)^{2}+6\left(\tau_{x y}^{2}+\tau_{y z}^{2}+\tau_{z x}^{2}\right)\right],
\end{aligned}
$$

When microelement body had only principal stress along normal direction, we get the following equation:

$$
\left\{\begin{array}{l}
\sigma_{x}=\sigma_{1}, \sigma_{y}=\sigma_{2}, \sigma_{z}=\sigma_{3}, \\
\tau_{x y}=\tau_{y x}=\tau_{y z}=\tau_{z y}=\tau_{x z}=\tau_{z x}=0 .
\end{array}\right.
$$

When certain stress conditions are met, materials yield. The Mises yielding condition is one of the most commonly applied yielding conditions. The experimental studies have revealed that the Mises yielding condition better described the yielding behaviors of metallic materials with good ductility. In yielding state, considering the Mises yield criterion and substituting equation (13) into equation (12), the second invariant of deviatoric stress $\left(J_{2}^{s}\right)$ when hollow tubes were stretched was as follows:

$$
\begin{aligned}
J_{2}^{s} & =\frac{1}{6}\left[\left(\sigma_{1}-\sigma_{2}\right)^{2}+\left(\sigma_{2}-\sigma_{3}\right)^{2}+\left(\sigma_{1}-\sigma_{3}\right)^{2}\right] \\
& =\frac{\sigma_{s}^{2}}{3} .
\end{aligned}
$$

In principal stress space, the Mises yield surface was represented as a cylinder parallel to hydrostatic compressor axis (Figure 3(a)). The intersection of the cylinder and $\sigma_{1}-$ $\sigma_{2}$ plane formed an ellipse (Figure 3(b)). In plane stress state, i.e., when $\sigma_{3}=0$, the elliptic equation obtained from equation (14) was as follows:

$$
\sigma_{1}^{2}-\sigma_{1} \sigma_{2}+\sigma_{2}^{2}-\sigma_{s}^{2}=0
$$

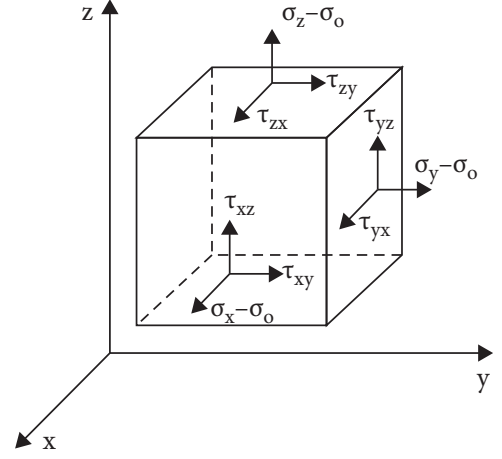

FIgURE 2: Deviator stress state.

Transformation of equation (15) yielded the following:

$$
\left(\frac{\sigma_{1}}{\sigma_{s}}\right)^{2}-\frac{\sigma_{1}}{\sigma_{s}} \frac{\sigma_{2}}{\sigma_{s}}+\left(\frac{\sigma_{2}}{\sigma_{s}}\right)^{2}-1=0 .
$$

As shown in Figure 3(b), when materials were in plane stress state, with the increase in stress along one direction yield stress along the other direction was increased and then decreased. The derivation of equation (16) with respect to $\sigma_{2} / \sigma_{s}$ revealed that when $\left(\sigma_{2} / \sigma_{s}\right)=(1 / \sqrt{3})$, the value of $\sigma_{1} / \sigma_{s}$ was maximum; i.e., $\left(\sigma_{1} / \sigma_{s}\right)_{\max }=2 / \sqrt{3} \approx 1 \cdot 155$. In other words, under bidirectional tensile conditions, yield stress could be increased by up to $15.5 \%$.

2.4. Size Effects on Filled Tubes under Tension. Stresses on the inner surfaces of tensile circular tubes with supporting materials and the outer surfaces of internal supports are shown in Figure 4(a) and 4(b), respectively. Ignoring frictional shear stress $\tau_{f}$ on the inner surface of tube wall, the pipe wall was in a three-way stress state (axial stress $\sigma_{l}$, cylinder stress $\sigma_{t}$, and radial stress $-p$ ). Due to steel tube extrusion, internal supporting materials were subjected to compressive stresses $-p$.

According to the single curve hypothesis [23], $J_{2}^{s}$ in the yield states of filled steel tubes under tension was equal to those of corresponding hollow tubes. Therefore, the yield functions of filled tubes under yielded state satisfied equation (15).

Since wall thickness $t$ was lower than the inner radius $r$ of circular tubes, the gradient of $\sigma_{t}$ along radius could be ignored. According to the principle of the equilibrium of forces (as shown in Figure 4(c)), it could be stated that

$$
\begin{aligned}
\sigma_{t} & =\frac{\int_{0}^{\pi} r p \sin \varphi \mathrm{d} \varphi}{2 t} \\
& =\frac{r p}{t} \\
& =\lambda p .
\end{aligned}
$$

Defining radius-to-thickness ratio as $\lambda=r / t$,

$$
\sigma_{t}=\lambda p .
$$




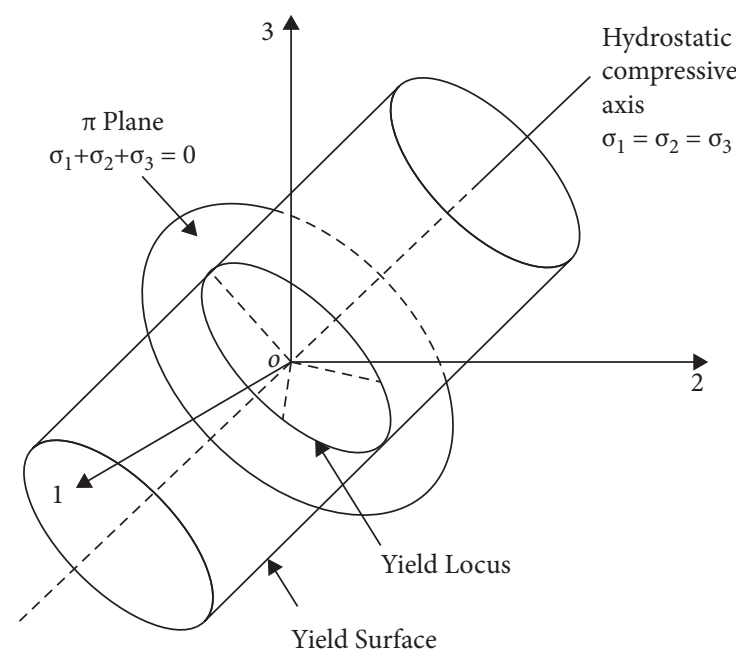

(a)

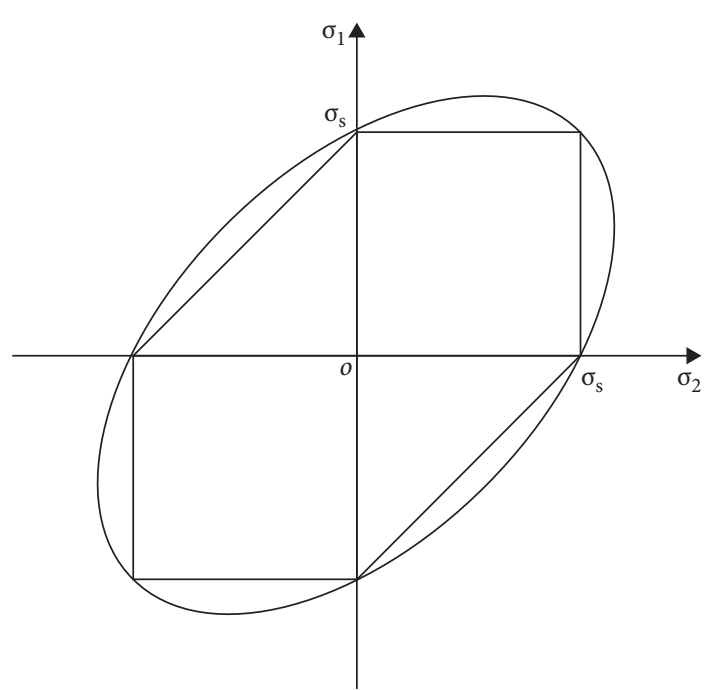

(b)

Figure 3: (a) Mises yield surface in principal stress space. (b) Intersection line of cylinder and $\sigma_{1}-\sigma_{2}$ plane.

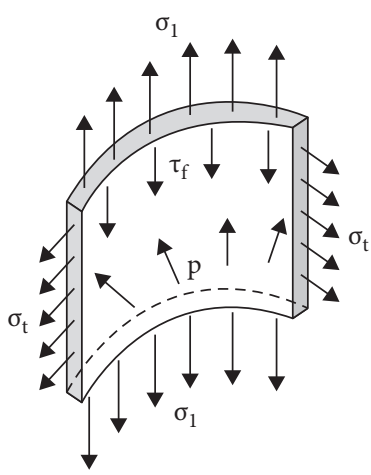

(a)

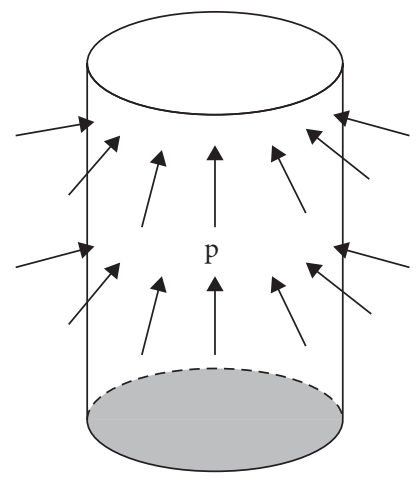

(b)

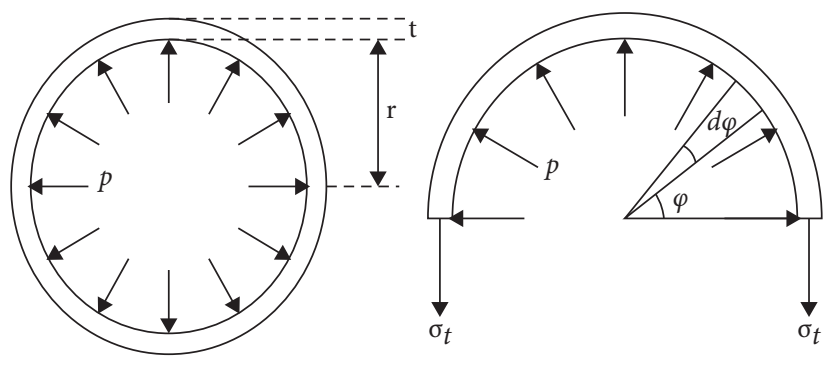

(c)

FIGURE 4: Stress conditions of (a) steel tubes, (b) internal supporting materials, and (c) cross section of filled tube.

Based on generalized Hooke's law,

$$
\begin{aligned}
\varepsilon_{t} & =\frac{\sigma_{t}}{E}-\frac{\mu\left(\sigma_{l}+\sigma\right)_{r}}{E}, \\
\varepsilon_{t, \text { in }} & =\frac{\sigma_{t, \text { in }}}{E_{\text {in }}}-\frac{\mu_{\text {in }}\left(\sigma_{l, \text { in }}+\sigma_{r, \text { in }}\right)}{E_{\text {in }}} .
\end{aligned}
$$

Since steel tubes and internal supporting materials satisfied circumferential deformation coordination, we state that:

$$
\varepsilon_{t}=\varepsilon_{t, \text { in }} .
$$

For external steel tubes,

$$
\left\{\begin{array}{l}
\sigma_{t}=\lambda p \\
\sigma_{r}=-p
\end{array}\right.
$$

For internal supporting materials,

$$
\left\{\begin{array}{l}
\sigma_{r, \text { in }}=\sigma_{t, \text { in }}=-p, \\
\sigma_{l, \text { in }}=\tau_{f}=0 .
\end{array}\right.
$$

Substituting equations (19) and (20) into equation (21) resulted in the following equation:

$$
\frac{\sigma_{t}-\mu\left(\sigma_{l}-p\right)}{E}=\left(1-\mu_{\text {in }}\right) \frac{-p}{E_{\text {in }}} \otimes .
$$

By considering equations (22) and (23) and eliminating $p$ in equation (24), we obtain the following:

$$
\sigma_{t}=\frac{\lambda \mu}{(\lambda+\mu)+E / E_{\text {in }}\left(1-\mu_{\text {in }}\right)} \sigma_{l} .
$$

Defining $\omega_{s}=\lambda \mu /(\lambda+\mu)+E / E_{\text {in }}\left(1-\mu_{\text {in }}\right)$,

$$
\sigma_{t}=\omega_{s} \sigma_{l}
$$

By substituting $\sigma_{l}$ and $\sigma_{t}$ into equation (15), one can obtain the following: 


$$
\sigma_{l}^{2}-\sigma_{l} \sigma_{t}+\sigma_{t}^{2}=\sigma_{s}^{2} .
$$

Substitution of equation (26) into equation (27) achieved the calculation equation of the yield strength of filled steel tubes as follows:

$$
\sigma_{l}=\sqrt{\frac{1}{1-\omega_{s}+\omega_{s}^{2}}} \sigma_{s}
$$

When $\mu=0 \cdot 3$ and $E=210 \mathrm{GPa}$, the trend of steel tube reinforcement coefficient $\sqrt{1 /\left(1-\omega_{s}+\omega_{s}^{2}\right)}$ as functions of $\lambda$, $E_{\text {in }}$, and $\mu_{\text {in }}$ is shown in Figure 5 .

The following conclusions could be drawn from Figure 5 . (1) Under the same support stiffness conditions, the increase in steel tubes radius-to-thickness ratio $\lambda$ increased reinforcement coefficient. (2) By increasing the elastic modulus of internal supporting material, the reinforcement coefficient was increased. (3) When $E_{\text {in }} \longrightarrow \infty$ and $\lambda \longrightarrow \infty$, $\sqrt{1 /\left(1-\omega_{s}+\omega_{s}^{2}\right)_{\max }}=1 \cdot 125<1 \cdot 155$. In other words, the reinforcement coefficient could not reach theoretical maximum value (1.155) by adjusting the elastic modulus of internal supporting material. (4) The reinforcement coefficient was increased with the increase in Poisson's ratio $\mu_{\text {in }}$ of internal supporting material; however, the reinforcement coefficient was not sensitive to $\mu_{\text {in }}$.

From equations (18) and (25),

$$
p=\frac{\mu}{(\lambda+\mu)+E / E_{\text {in }}\left(1-\mu_{\text {in }}\right)} \sigma_{l} .
$$

According to generalized Hooke's law, longitudinal strain $\varepsilon_{l}$ of the tube is as follows:

$$
\varepsilon_{l}=\frac{\sigma_{l}}{E}-\frac{\mu(\lambda-1) p}{E}
$$

Substituting equation (29) into equation (30) concluded the following:

$$
\begin{aligned}
\varepsilon_{l} & =\left[1-\frac{(\lambda-1) \mu^{2}}{(\lambda+\mu)+E / E_{i n}\left(1-\mu_{i n}\right)}\right] \frac{\sigma_{l}}{E} \\
& =\left[1-\frac{\mu(\lambda-1)}{\lambda} \omega_{s}\right] \frac{\sigma_{l}}{E},
\end{aligned}
$$

where $\sigma_{l} / E$ is longitudinal strain when hollow tube is stretched. When $\mu=0 \cdot 3$ and $E=210 \mathrm{GPa}$, the trend of steel tube deformation weakening coefficient $\left[1-\mu(\lambda-1) / \lambda \omega_{s}\right]$ as functions of $\lambda, E_{\text {in }}$, and $\mu_{\text {in }}$ is shown in Figure 6. The deformation weakening coefficient $\left[1-\mu(\lambda-1) / \lambda \omega_{s}\right]$ indicates the ability of filled tubes to resist axial deformation. The higher value of $\left[1-\mu(\lambda-1) / \lambda \omega_{s}\right]$ means the lower ability of filled tubes to resist axial deformation.

The following conclusions are drawn from Figure 6. (1) Under similar support stiffness conditions, the increase in radius-to-thickness ratio $\lambda$ decreased deformation weakening coefficient. To achieve similar deformation as the hollow tube, filled tubes can withstand greater load, reflecting the energy consumption characteristics of filled tubes. (2) Increasing the elastic modulus of internal supporting material decreased deformation weakening

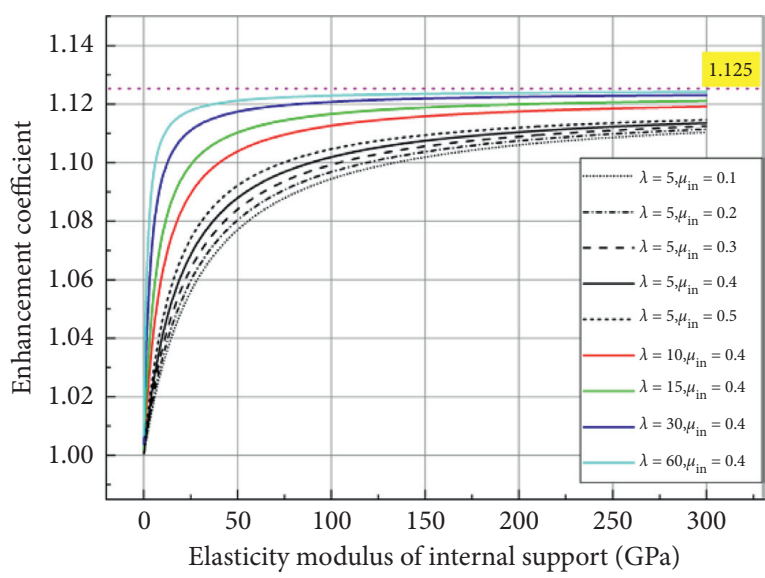

FIgURE 5: Trends of tensile strength reinforcement coefficient as functions of $\lambda, E_{\mathrm{in}}$, and $\mu_{\mathrm{in}}$.

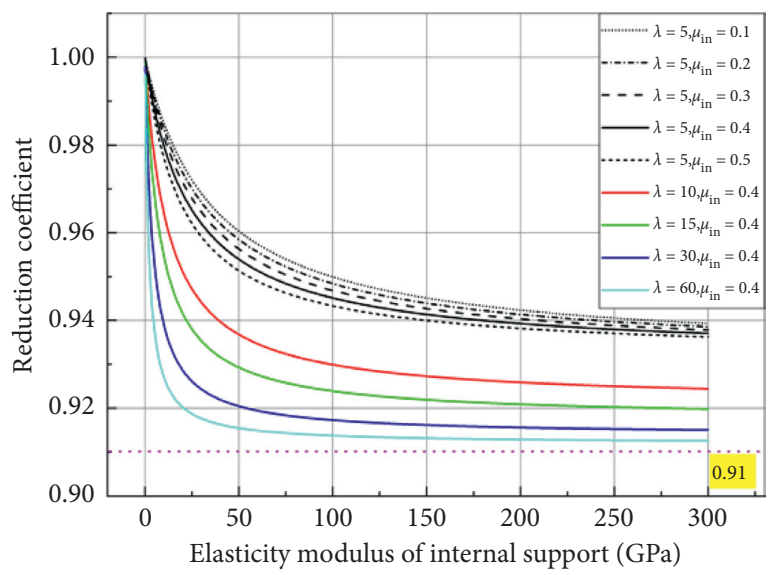

FIgURE 6: Variations of deformation weakening coefficient as functions of $\lambda, E_{\text {in }}$, and $\mu_{\text {in }}$.

coefficient. (3) When $E_{\text {in }} \longrightarrow \infty$ and $\lambda \longrightarrow \infty$, $\left[1-\mu(\lambda-1) / \lambda \omega_{s}\right]_{\min }=0 \cdot 91$. (4) The deformation weakening coefficient was decreased by increasing Poisson's ratio $\mu_{\text {in }}$ of internal supporting material; however, the deformation weakening coefficient was not sensitive to $\mu_{\text {in }}$.

\section{Influences of Section Pattern on Internal Supporting Effect}

Regarding the influence of section pattern on internal supporting effect, most researchers have investigated circular section patterns $[6-12,14,15,17-19]$. Li et al. [13] conducted axial tension tests on CFDST components, considering that tensile strength was due to both outer and inner tubes and applying coefficient of 1.1 to take into account the strength enhancement of outer tube. Zhou et al. [16] performed an experimental study on SCFST components under axial tension and found that the tensile strengths of SCFSTs were 5.2\% higher than corresponding hollow tubes. However, the corresponding tensile strength of circular concrete-filled steel tubes (CCFSTs) was increased by $10.2 \%[24]$. 
This article has mainly adopted ANASYS Software to develop a finite element analysis model. The circular and square sections were analyzed and compared.

3.1. ANSYS Finite Element Analysis Model. To evaluate the influences of different cross-sectional forms on internal support, this study established the finite element analysis model of circular and square cross sections. Numerical simulation was performed in the following steps:

(a) Establishing the finite element analysis model.

The finite element analysis models established by ANASYS 19.2 Software are shown in Figures 7 and 8. The outer diameter of circular steel tube was $30 \mathrm{~mm}$, with wall thickness of $2 \mathrm{~mm}$ and length of $100 \mathrm{~mm}$. The outer side length of square tube was $24 \mathrm{~mm}$, with wall thickness of $2 \mathrm{~mm}$ and length of $100 \mathrm{~mm}$. The circular cross section has the same cross-sectional area as the square one.

(b) Setting material parameters.

material of circular and square tubes was stainless steel NL and that of internal supporting material was concrete. The material parameters of stainless steel NL and concrete had default values as follows: elastic modulus of stainless steel $\mathrm{NL}=193 \mathrm{GPa}$ with plastic modulus $=1.8 \mathrm{GPa}$, Poisson's ratio $=0.31$, and yield strength $=210 \mathrm{MPa}$; and elastic modulus of concrete $=30 \mathrm{GPa}$ with Poisson's ratio $=0.18$.

(c) Establishing a cylindrical coordinate system.

A cylindrical coordinate system was established based on global coordinate system.

(d) Mesh dividing.

(e) Interface contact setting.

Connections between circular/square tubes and internal supporting materials were set to frictionless contact.

(f) Adding constraints and displacements.

Based on cylindrical coordinate system, one end of the thin-walled circular/square tube was set as a fixed end, and the other end was added with force.

(g) Solving the result.

According to Saint-Venant's principle, the solution result selected the maximum Mises equivalent stress of the middle section of tubes.

Figures 7 and 8 present finite element analysis models (ANASYS 19.2) for tubes with the circular and square sections, respectively.

3.2. Comparison of Circular and Square Sections. According to Saint-Venant's principle, the calculation results took the maximum Mises equivalent stress of the middle section of tubes (Figure 9).

When the maximum Mises equivalent stress of middle section reached corresponding value in Table 2, tension strength increases in circular and square tubes are compared as follows. The increased curves of tensile stresses of circular and square tubes are shown in Figure 10.

As presented in Table 2 and Figure 10, generally, the increase in internal support on the tensile load capacity of steel tubes was first increased and then decreased, reaching the maximum value after yield point. Meanwhile, circular tubes were more evenly loaded along all directions (Figure 9(a)) and square tubes had large stress concentrations at the vertex of edge length (Figure 9(b)). In addition, the increase in tensile force of internal support for circular tubes was greater than that for square tubes and there was no negative increase in circular tubes as shown in Table 2.

3.3. Optimization of Circular Sections. As discussed in Section 2.2, the maximum reinforcement coefficient was found to be 1.125. In other words, it was not possible to obtain the reinforcement coefficient of 1.155 by adjusting the elastic modulus of internal supporting material. Maximizing the reinforcement coefficient to fully utilize the reinforcing effect of internal supporting material requires further research.

As discussed in Section 3.2, the stress states of circular sections were better than those of square sections. However, for large diameter circular tubes under tension in engineering structures, supporting materials cause substantial increase in the weight of circular tubes and increase the cost of project. Therefore, the optimization of the section pattern of large diameter circular tubes with fillers deserves the attention of engineering designers.

To decrease the self-weight of structures, this study has proposed prestressed circular hollow support section, as depicted in Figure 11. The advantages of this structure included the following: (1) internal supporting material generated initial support prestress for steel tubes and improved reinforcement coefficient. (2) The hollow structure of internal supporting material reduced the self-weight, material consumption, and construction cost of the structure. (3) Internal hollow structure can be used to lay out the circuit, effectively using structural space. (4) Micro-expansion concrete could be used as supporting material. It was also possible to apply the cold shrinkage assembly method to achieve interference fit connection between support material and steel tube.

\section{Effect of Material on Internal Supporting Effect}

When studying components under tension, most researchers adopt ordinary low-carbon steel or stainless steel with certain specifications. However, the intrinsic structural relationships and elongation rates of various steels were different. Pan et al. [6] performed axial tensile tests on CFST components of three steel grades (A3, 16Mn, and $15 \mathrm{MnV}$ ) and found that the increase in the longitudinal yield stress of steel tubes was not mainly related to the grade of steel. The author only partially agrees with this view. In this study, six 


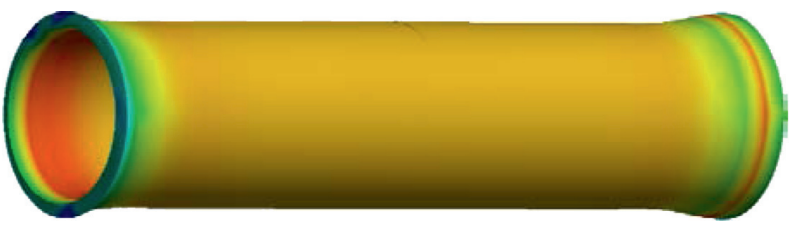

(a)

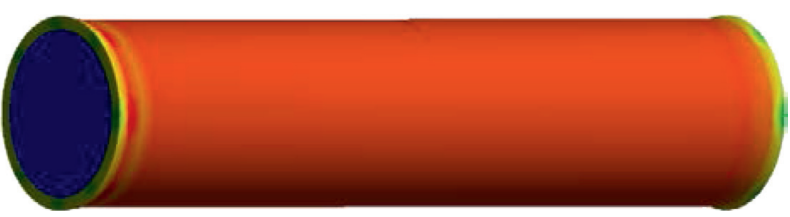

(b)

Figure 7: (a) Circular hollow tube under tension. (b) Circular tube with internal support under tension.

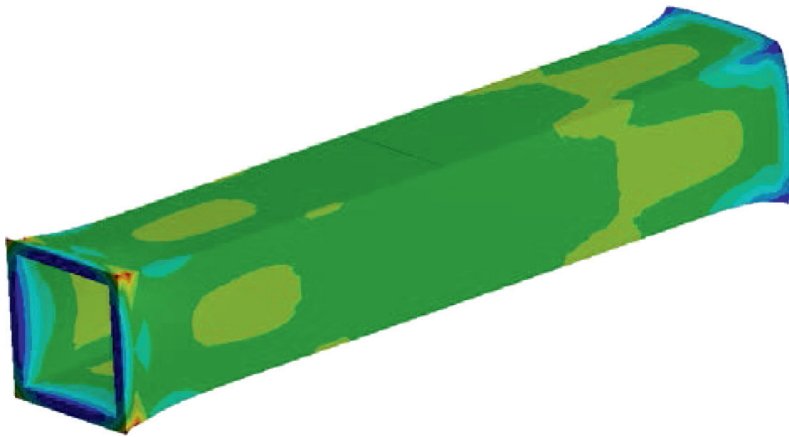

(a)

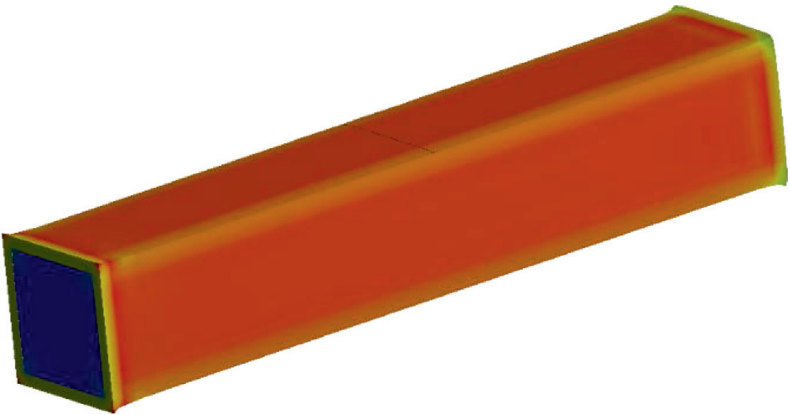

(b)

Figure 8: (a) Square hollow tube under tension. (b) Square tube with internal support under tension.

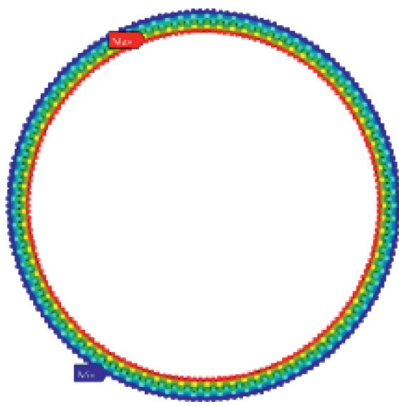

(a)

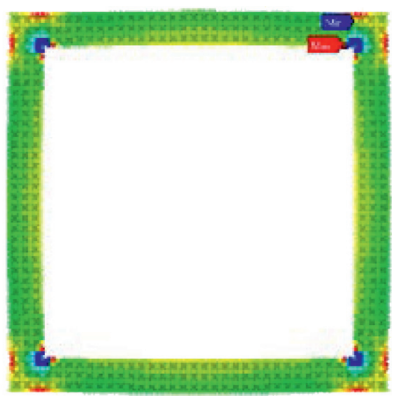

(b)

Figure 9: Maximum Mises equivalent stress of middle section: (a) circular tube and (b) square tube.

TABLE 2: Increase in tensile stresses of circular and square tubes.

\begin{tabular}{|c|c|c|c|c|c|c|}
\hline & $\begin{array}{l}\text { Circular hollow } \\
\text { tubes }(\mathrm{kN})\end{array}$ & $\begin{array}{c}\text { Circular tubes }+ \text { internal } \\
\text { support }(\mathrm{kN})\end{array}$ & $\begin{array}{c}\text { Increase in } \\
\text { tensile stress (\%) }\end{array}$ & $\begin{array}{l}\text { Square hollow } \\
\text { tubes }(\mathrm{kN})\end{array}$ & $\begin{array}{c}\text { Square tube }+ \text { internal } \\
\text { support }(\mathrm{kN})\end{array}$ & $\begin{array}{c}\text { Increase in } \\
\text { tensile stress (\%) }\end{array}$ \\
\hline $10 \mathrm{MPa}$ & 1.76 & 1.85 & 5.11 & 1.76 & 1.75 & -0.57 \\
\hline $50 \mathrm{MPa}$ & 8.80 & 9.29 & 5.57 & 8.80 & 8.76 & -0.45 \\
\hline $100 \mathrm{MPa}$ & 17.60 & 18.62 & 5.80 & 17.60 & 17.52 & -0.45 \\
\hline $150 \mathrm{MPa}$ & 26.40 & 27.94 & 5.83 & 26.40 & 26.27 & -0.49 \\
\hline $200 \mathrm{MPa}$ & 35.19 & 37.28 & 5.94 & 35.19 & 35.02 & -0.48 \\
\hline $220 \mathrm{MPa}$ & 38.71 & 43.10 & 11.34 & 38.72 & 41.93 & 8.29 \\
\hline $250 \mathrm{MPa}$ & 43.99 & 49.05 & 11.50 & 44.00 & 47.70 & 8.41 \\
\hline $300 \mathrm{MPa}$ & 52.79 & 58.73 & 11.25 & 52.80 & 55.11 & 4.38 \\
\hline $350 \mathrm{MPa}$ & 61.58 & 68.41 & 11.09 & 61.59 & 62.19 & 0.97 \\
\hline $400 \mathrm{MPa}$ & 70.37 & 78.08 & 10.96 & 70.39 & 69.15 & -1.76 \\
\hline $450 \mathrm{MPa}$ & 79.16 & 87.75 & 10.85 & 79.19 & 76.25 & -3.71 \\
\hline $500 \mathrm{MPa}$ & 87.96 & 97.42 & 10.75 & 88.00 & 83.04 & -5.64 \\
\hline
\end{tabular}

types of tubes with different elongation rates were adopted to evaluate the influence of elongation after fracture of tube on internal supporting effect.
4.1. Sample Preparation. Figure 12 presents a standard circular thin-walled tube prepared according to ISO6892-1 metallic materials-tensile testing. Specimen specifications 


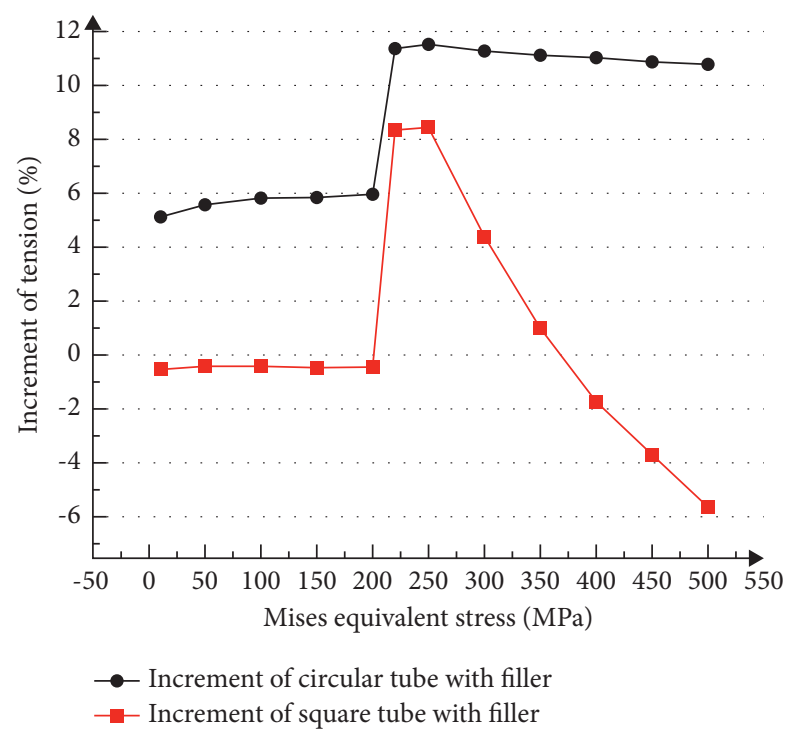

FIGURE 10: Increase in tensile stresses of circular and square tubes.

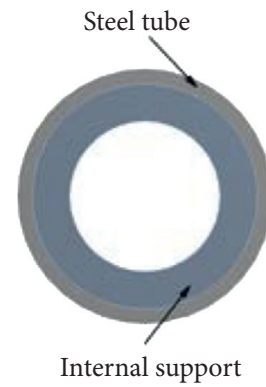

(a)

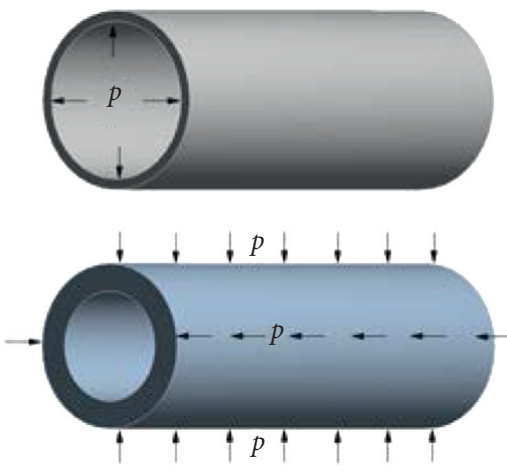

(b)

FIgURE 11: (a) Prestressed circular hollow support section. (b) Initial prestress of steel tubes caused by internal support. $p=$ initial support prestress.

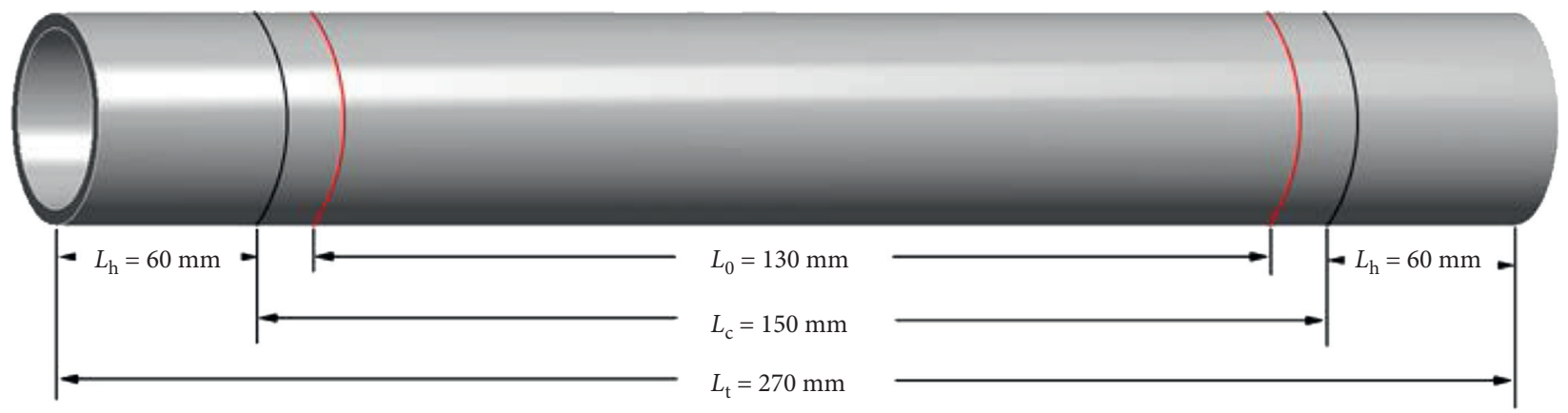

FiguRe 12: Standard circular thin-walled tube.

were original gauge length $L_{0}=130 \mathrm{~mm}$, parallel length $L_{c}=150 \mathrm{~mm}$, clamping length $L_{h}=60 \mathrm{~mm}$, and total length $L_{t}=270 \mathrm{~mm}$.

Circular thin-walled tubes made of six different materials, including 304 stainless steel, 16Mn steel, Q235 steel, $42 \mathrm{CrMo}$ steel, \#45 steel, and 6061 aluminum alloy, were adopted (Figure 13). Measured sizes are summarized in
Table 3. PTFE with measured elastic modulus of $231 \mathrm{MPa}$ was applied as internal supporting material [19]. The cold shrinkage assembly method was used to make PTFE produce a certain amount of initial support prestress on circular tubes.

No chemical bonding was performed between tube wall inner surface and supporting material during specimen 


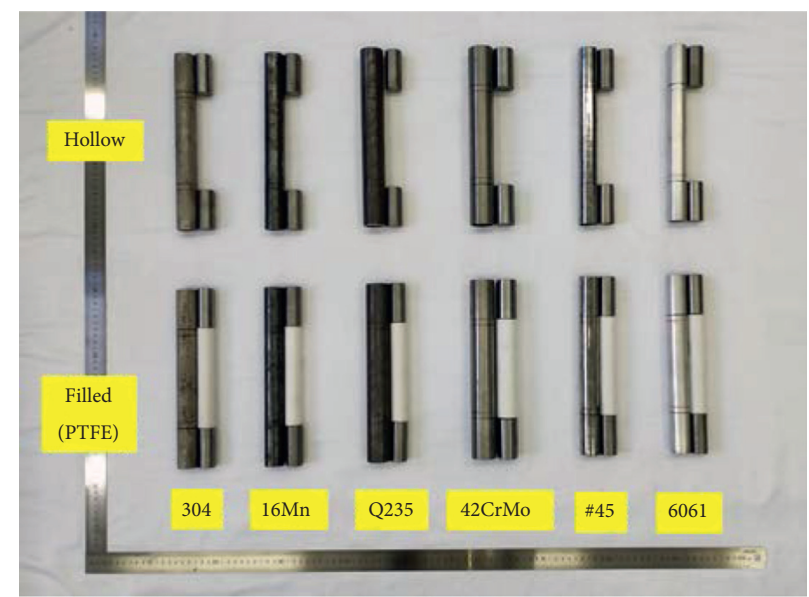

FIGURE 13: Circular thin-walled tubes made of six different materials. Hollow: hollow specimen; filled: PTFE-filled specimen.

TABLE 3: Sizes of circular thin-walled tubes made of six different materials.

\begin{tabular}{|c|c|c|c|c|c|c|}
\hline Material & 304 & $16 \mathrm{Mn}$ & Q235 & $\# 45$ & 42CrMo & 6061 \\
\hline External diameter $(\mathrm{mm})$ & 30.05 & 30.00 & 35.10 & 30.03 & 38.00 & 29.99 \\
\hline Internal diameter (mm) & 25.89 & 23.83 & 25.84 & 26.02 & 32.19 & 25.85 \\
\hline Wall thickness (mm) & 2.08 & 3.09 & 4.63 & 2.01 & 2.91 & 2.07 \\
\hline Cross-sectional area $\left(\mathrm{mm}^{2}\right)$ & 182.77 & 260.86 & 443.20 & 176.53 & 320.29 & 181.57 \\
\hline
\end{tabular}

fabrication (as shown in Figure 14) to maximize the simulation of frictionless contact between the two.

4.2. Tensile Fracture Test. The loading device was microcomputer-controlled electrohydraulic servo universal testing machine (Shenzhen Wance 100-ton HUT106D, located at the Army Engineering University of PLA in Nanjing, China). The axial strain rate was set to $15 \mathrm{~mm} / \mathrm{min}$ [19]. Four effective specimens were stretched under each working condition, and the macroscopic morphologies of specimens made of different materials after fracture are presented in Figure 15. Also, the tensile load-displacement curves of specimens made of different materials are shown in Figure 16. Table 4 compares test data obtained for each group of specimens.

4.3. Outlook. In 304 stainless steel, PTFE provided the highest tensile performance improvement. The average increases in yield force, ultimate bearing capacity, elongation after fracture, and fracture energy were found to be $10.81 \%, 15.35 \%, 19.33 \%$, and $47.38 \%$, respectively. The elongation after fracture of material was an important factor in improving the tensile performance of PTFE-filled tubes. When elongation after fracture $>17 \%$, all tensile parameters of tubes presented positive growth rates (e.g., 304 stainless steel, 16Mn, and Q235 specimens). On the other hand, when elongation after fracture $<17 \%$, yield force and ultimate bearing capacity of tubes were slightly increased; however, elongation after fracture and fracture energy presented negative growth rates (e.g., \#45, 42CrMo, and 6061 specimens). Prestressed internal support effectively increased the yield force and ultimate bearing capacity of tubes. For metallic materials with high ductility, due to the supporting effect of prestressed internal filling material, the lateral necking of circular tubes to symmetry axis during tension was slowed down, which significantly improved the tensile performance, fracture toughness, and energy consumption of test specimens. Therefore, this arrangement could be applied in energyabsorbing structures such as road tubular guardrails and played an important role in improving safety and decreasing life and property losses.

Regarding the interaction of $p$ and $\tau_{f}$, Zhu [17] and Hang [18] conducted experimental and numerical research works on steel-polyurethane (PU) components. By further analyzing their findings, the advantages of steel-PU structure were identified as summarized below:

(1) Lightweight and high strength. The density of PU was only $1 / 7$ of that of steel, and the mass of steel-PU with equal strength was $40 \% \sim 55 \%$ less than that of steel structure; the tensile and compressive properties were also more balanced.

(2) High corrosion and fatigue resistance. PU core material could disperse stress and therefore reduce stress concentration.

(3) Shock absorption, noise reduction, impact resistance. When exposed to extreme stress conditions such as collision, stranding, underwater, or surface explosive impacts, PU structures could absorb a great amount of energy through plastic deformation and improve structural safety.

(4) Convenient construction and maintenance. When performing onsite construction, there was no need for cutting the original structure, and only a cavity 


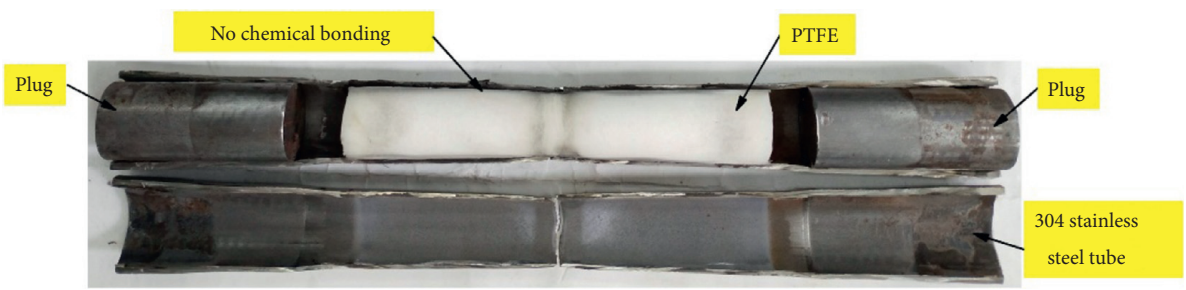

FIgURE 14: Sectional view of tensile steel tube filled with PTFE.

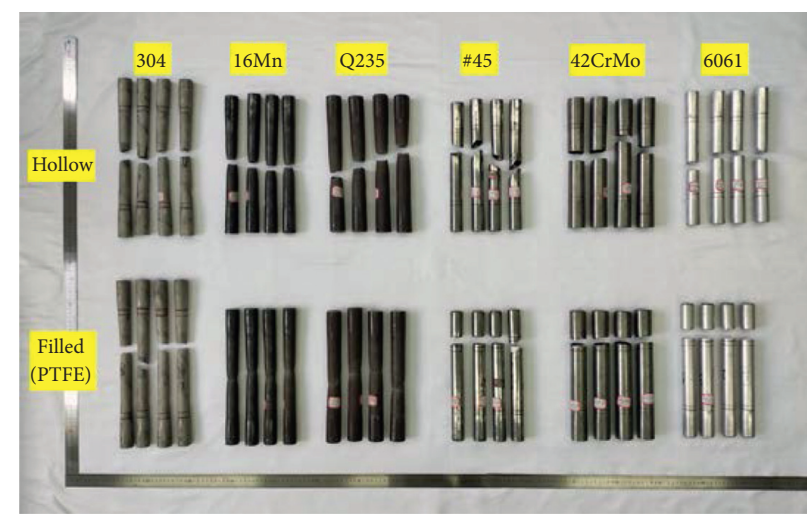

FIgURE 15: Fracture macroscopic morphology of components of different materials.

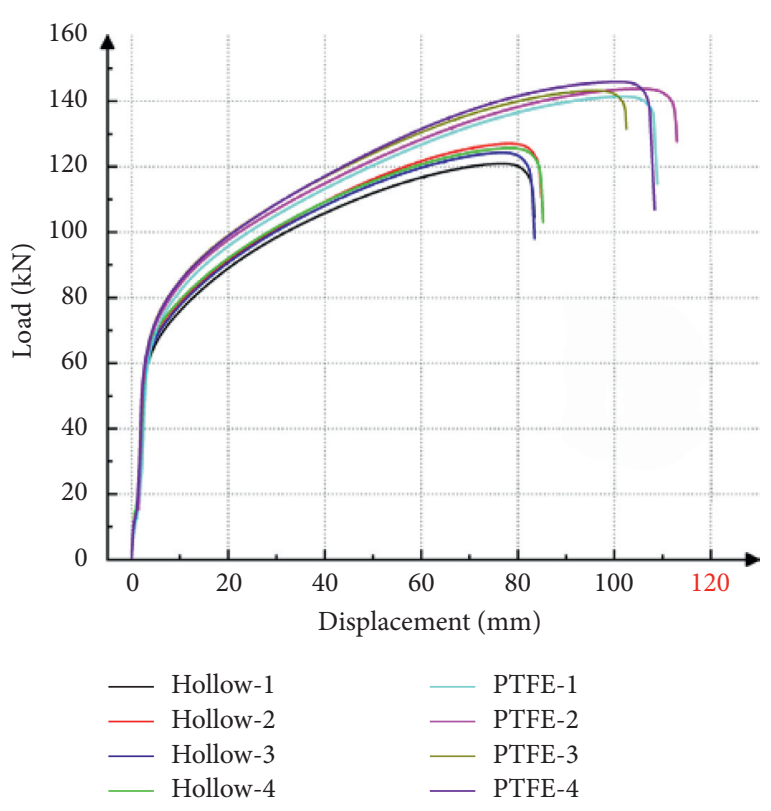

(a)

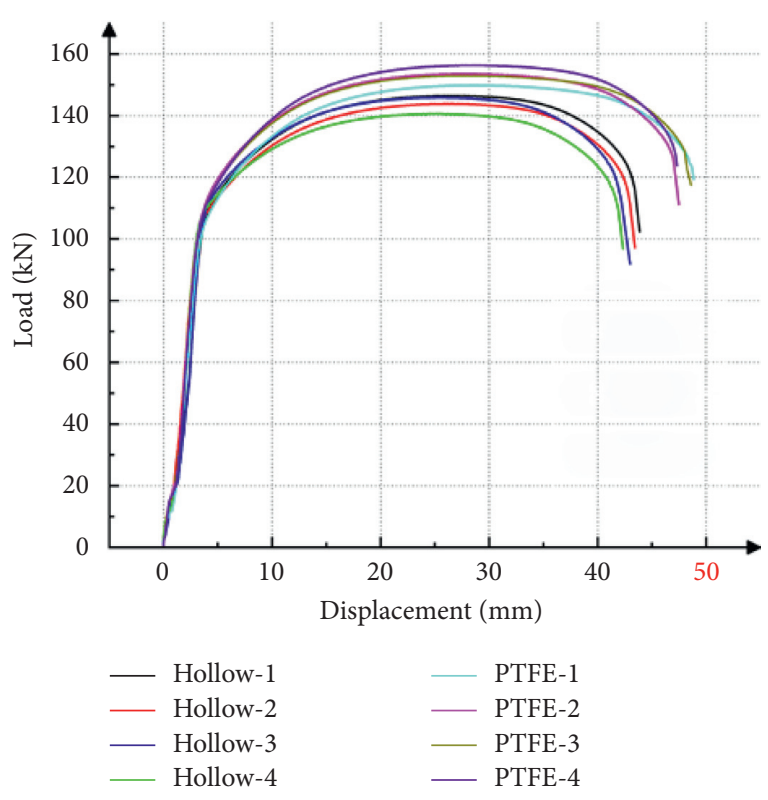

(b)

Figure 16: Continued. 

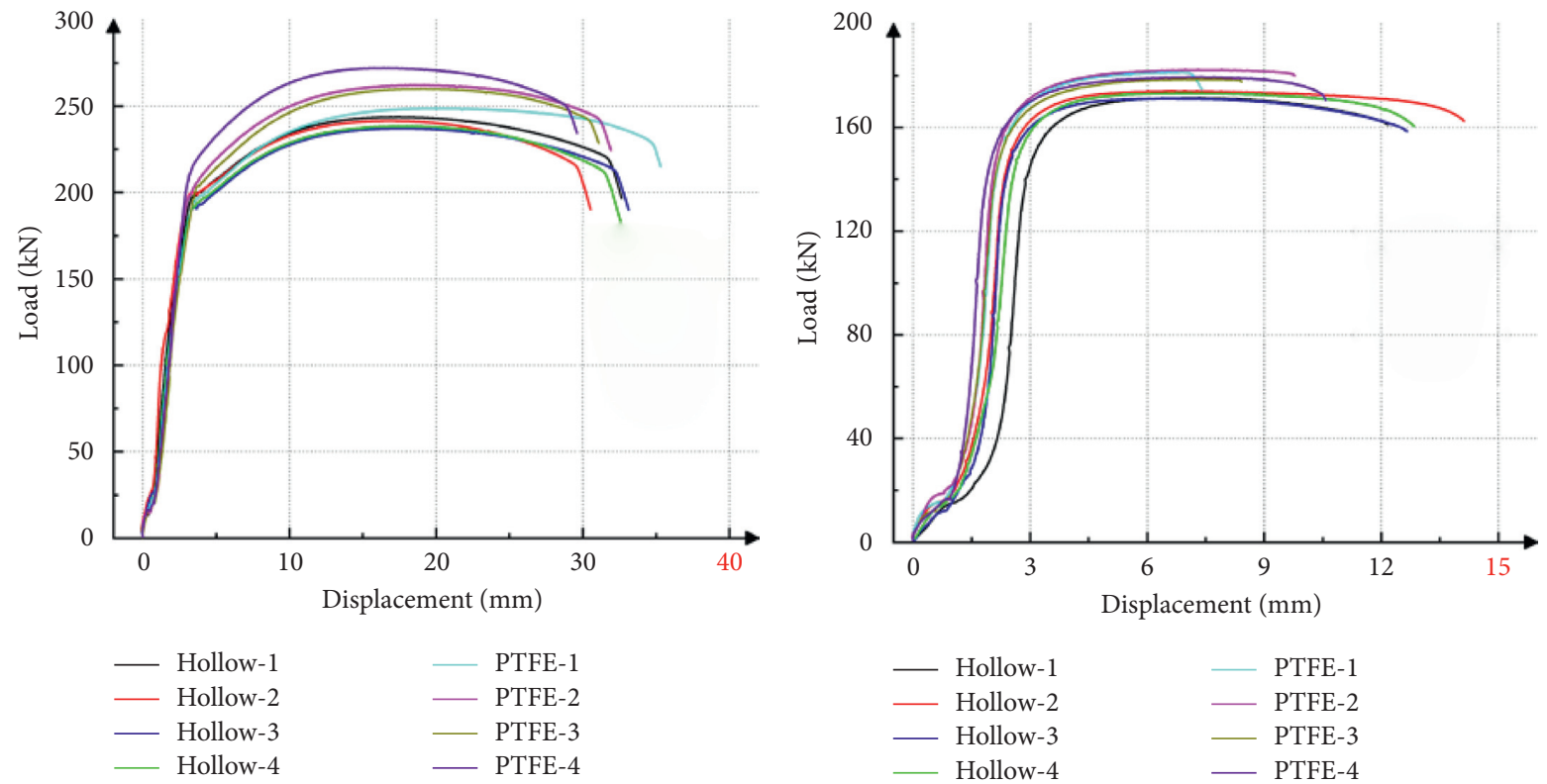

(c)

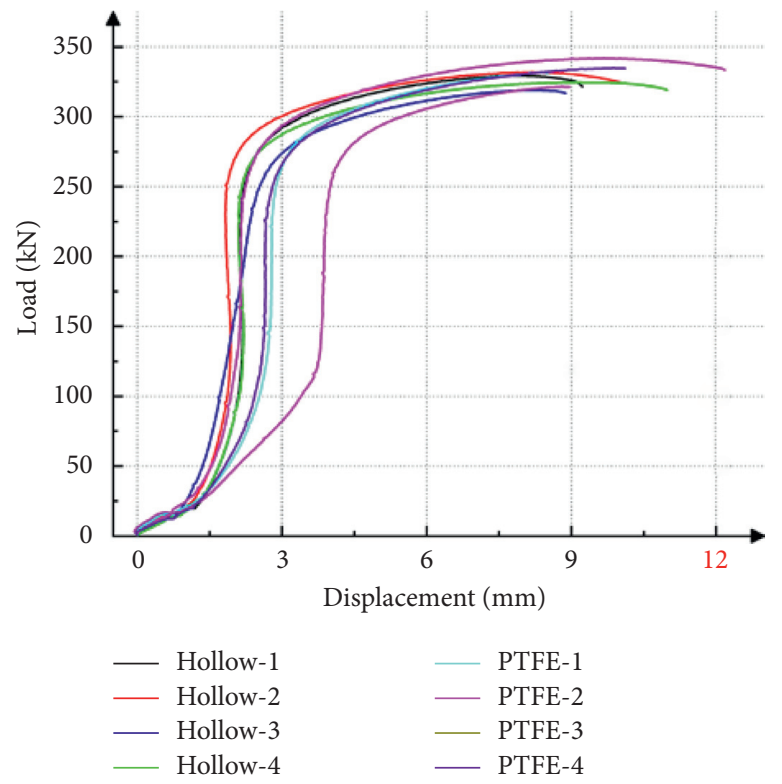

(e)

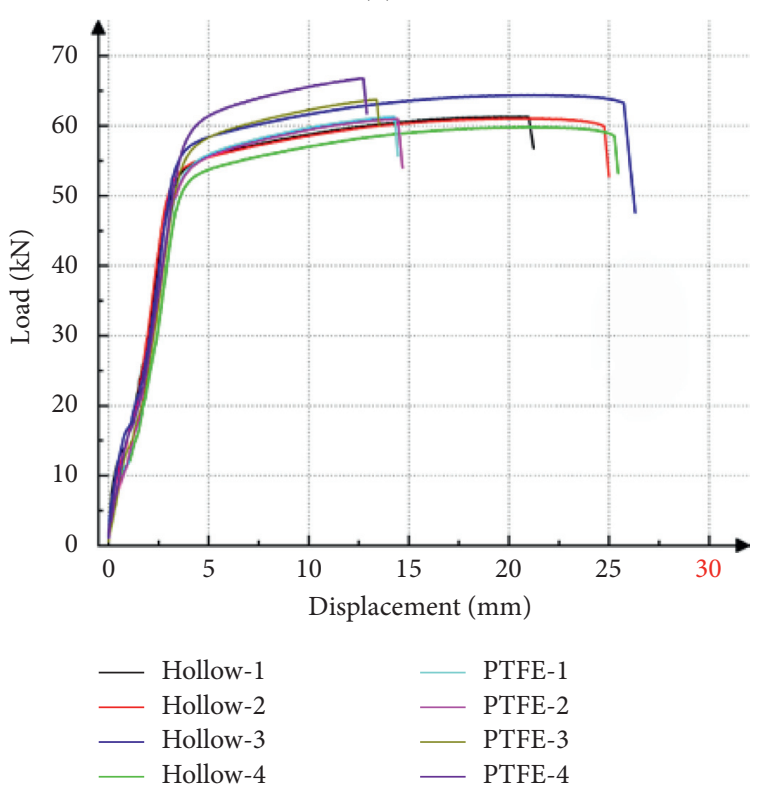

(f)

Figure 16: Load-displacement curve of components of different materials: (a) 304, (b) 16Mn, (c) Q235, (d) \#45, (e) 42CrMo, and (f) 6061.

was required for perfusion on the surface of original structure to directly pour PU elastomer into the cavity. Therefore, the construction period was short. During maintenance, secondary infusion and original PU compartments presented good bonding properties.
Steel-PU composite components have been extensively applied in marine jackets and other applications $[17,18]$, as shown in Figure 17. Furthermore, during repeated erection and withdrawal cycles of military equipment such as truss trestle bridges and heavy support bridges, the structure has more strict requirements in terms of the ability of rods to 


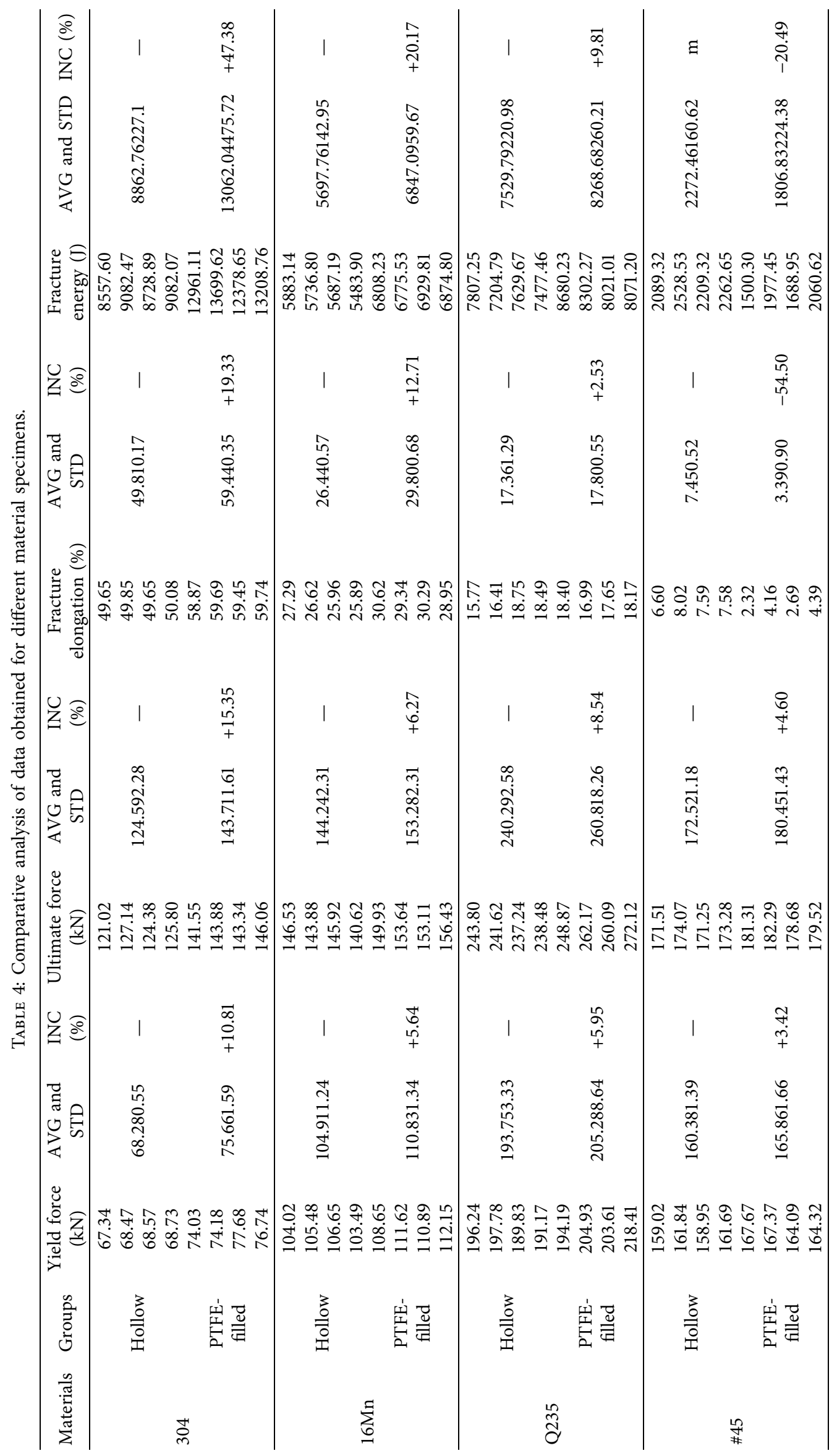




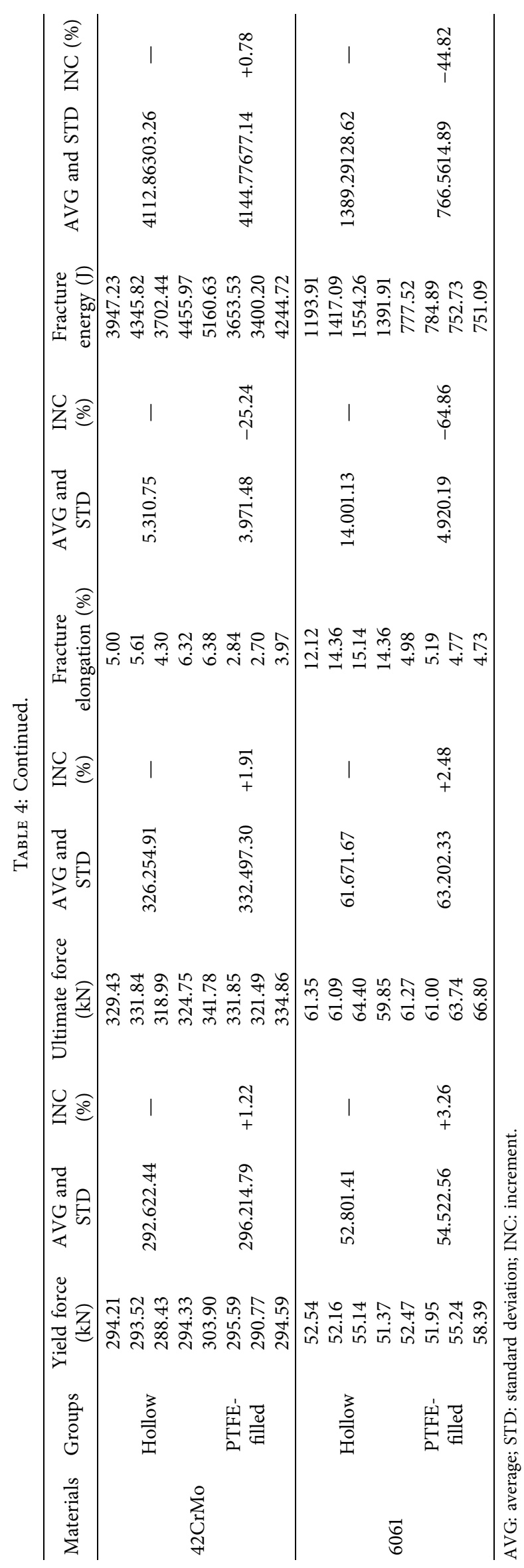




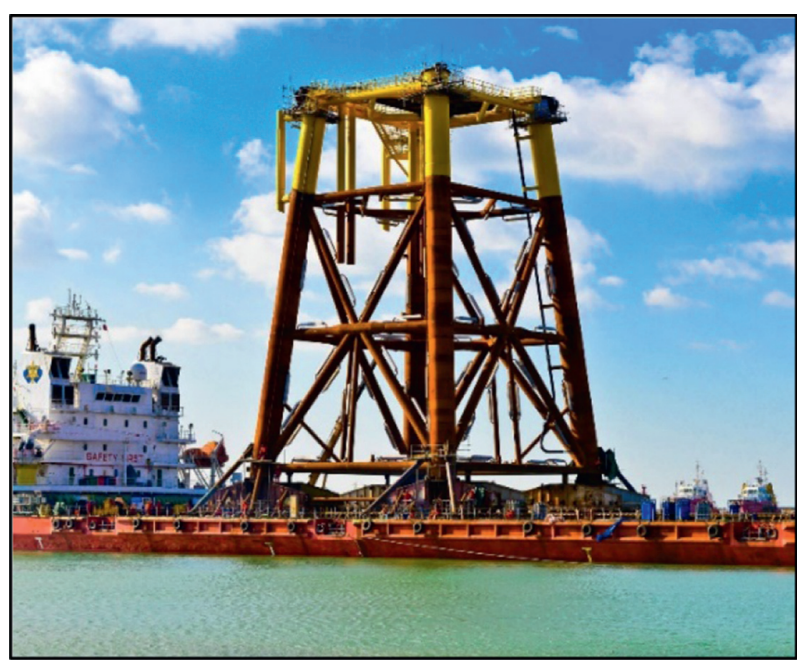

FIGURE 17: Offshore platform jacket.

withstand tensile and compressive cyclic loads, while steelPU components are lightweight, high strength, and balanced under tension and compression. The characteristics of these structures can better meet the relevant technical requirements.

\section{Conclusions}

In the current research, the following conclusions were made:

(1) tensile strength reinforcement coefficient was positively correlated with $\lambda, E_{\text {in }}$, and $\mu_{\text {in }}$, and the deformation weakening coefficient was negatively correlated with $\lambda, E_{\mathrm{in}}$, and $\mu_{\mathrm{in}}$. However, both were insensitive to the variations of $\mu_{\text {in }}$. The maximum reinforcement coefficient and minimum deformation weakening coefficient were 1.125 and 0.91 , respectively. To achieve the same tensile strength and deformation as the hollow tube, filled tubes can withstand greater load, reflecting the energy consumption characteristics of the filled tubes.

(2) circular section was found to perform better than square section. The increase in the tensile capacity of internal support for circular tubes was greater than that for square tubes, and there was no negative increment in circular tubes. The overall increase in the tensile load capacity of steel tubes by internal support was first increased and then decreased.

(3) Among the 6 different materials tested, the tensile performance of 304 stainless steel thin-walled circular tubes presented the greatest improvement. The maximum increases in yield force, ultimate bearing capacity, elongation after fracture, and fracture energy were found to be $10.81 \%, 15.35 \%, 19.33 \%$, and $47.38 \%$, respectively. The elongation after fracture of material was an important factor affecting the improvement of tensile performance of PTFE-filled tubes. When elongation after fracture $>17 \%$, all tensile parameters of tubes presented positive growth rate, while at elongation after fracture $<17 \%$, yield stress and ultimate bearing capacity of tubes were slightly increased; however, elongation after fracture and fracture energy presented negative growth rates.

(4) The tensile/compression yield forces of steel-PU composite tubes were much higher than those of hollow tube. The quality of the steel-PU composite tube of equal strength was $40 \% \sim 55 \%$ less than that of the steel structure, and its tensile and compressive properties were more balanced. Steel-PU composite pipe has the advantages of lightweight, high strength, corrosion resistance, fatigue resistance, vibration reduction, and noise reduction, as well as convenient construction and maintenance.

Prestressed internal support effectively increased the yield force and ultimate bearing capacity of tubes. For metallic materials with high ductility, due to the supporting effect of prestressed internal filling materials, the lateral necking of the circular tubes to symmetry axis during tension was slowed down, which significantly improved the tensile performance, fracture toughness, and energy consumption of circular tubes. However, there are still some unsolved problems such as the following issues: currently, $p$ value can only be estimated by theoretical and numerical methods; combinational optimization of steel tube material, steel tube section, and internal support material is difficult; further development of sandwich structures is required to decrease structure weight. These are all potential research topics worthy of the attention of researchers.

\section{Abbreviations}

CFSST: Concrete-filled stainless steel tube CFDST: Concrete-filled double skin steel tube

CCFST: Circular concrete-filled steel tube

CECFST: Concrete-encased concrete-filled steel tube

AECFST: Angle-encased concrete-filled steel tube

SCFST: Square concrete-filled steel tube

PFST: $\quad$ PU-filled steel tube

PFDST: PU-filled double skin steel tube

ABS: Acrylonitrile butadiene styrene plastic

SSTWT: Stainless steel thin-walled tube

$\mathrm{J}_{2}$ : $\quad$ Second invariant of deviatoric stress $\left(\mathrm{MPa}^{2}\right)$

$E: \quad$ Elastic modulus of steel tube $(\mathrm{MPa})$

$E_{\text {in }}$ : $\quad$ Elastic modulus of internal support $(\mathrm{MPa})$

$h: \quad$ Plastic modulus of tube $(\mathrm{MPa})$

$\sigma_{s}: \quad$ Yield stress of tube (MPa)

$\sigma_{l}$ : Longitudinal tensile stress of tube ( $\left.\mathrm{MPa}\right)$

$\sigma_{l, \text { in }}$ : Longitudinal tensile stress of internal support (MPa)

$\sigma_{t}: \quad$ Hoop tensile stress of tube ( $\left.\mathrm{MPa}\right)$

$\sigma_{t, \text { in }}: \quad$ Hoop tensile stress of internal support (MPa)

$\sigma_{r}: \quad$ Radial compressive stress of tube (MPa)

$\sigma_{r, \text { in }}: \quad$ Radial compressive stress of internal support (MPa) 


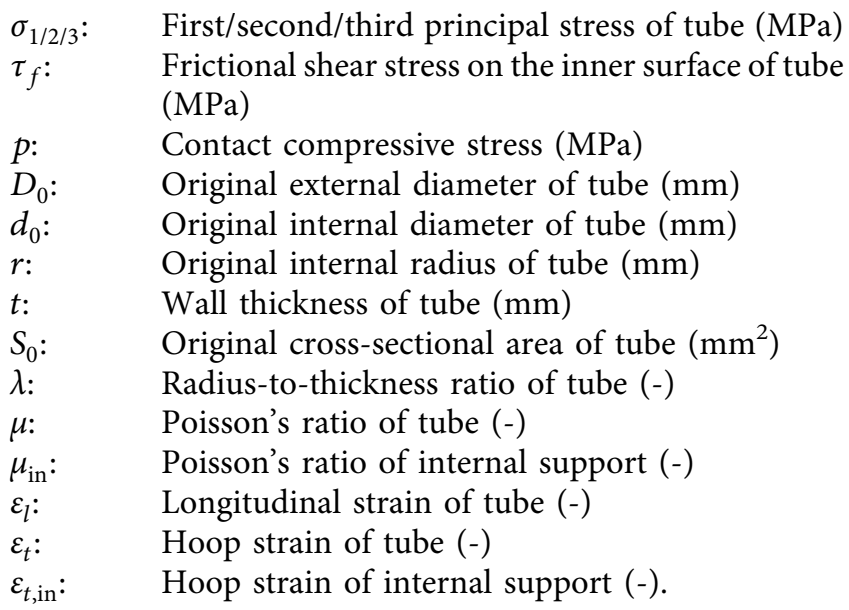

\section{Data Availability}

The data presented in this research are available on request from the corresponding author.

\section{Conflicts of Interest}

The authors declare no conflicts of interest.

\section{Authors' Contributions}

Y.G. and F.S. conceptualized the study; Y.G. and F.S. designed the methodology; Q.X., L.B., and Q.M. provided software; Q.X., L.B., and F.S. validated the data; L.G., Q.M., and Y.G. involved in formal analysis; Q.X. and L.B. investigated the data; M.S. and X.Y. provided resources; L.G. and Q.M. curated the data; Y.G. and F.S. wrote the original manuscript and prepared the draft; Y.G., F.S., and L.B. wrote, reviewed, and edited the manuscript; L.G. and Q.M. visualized the data; M.S. and X.Y. supervised the data; M.S., X.Y., and F.S. administered the project; and Y.G. and F.S. acquired funding. All authors have read and agreed to the published version of the manuscript.

\section{Acknowledgments}

This research was funded by the Postdoctoral Science Foundation of China, 2018M643852. The authors thank the MJEditor (www.mjeditor.com) for its linguistic assistance during the preparation of this manuscript.

\section{References}

[1] Z. Tao and Q. Yu, Innovative Composite Structural Column experiment Theory and Methodology, Science Press, Beijing, China, 2006, in Chinese.

[2] Recommendations for Design and Construction of Concrete Filled Steel Tubular Structures, Architectural Institute of Japan (AIJ), Tokyo, Japan, 2008.

[3] ANSI/AISC 360-05, Specification for Structural Steel Buildings, American Institute of Steel Construction (AISC), Chicago, USA, 2005.

[4] Eurocode 4, Design of Composite Steel and concrete Structures, Part1-1. General Rules and Rules for Buildings (EN 1994-1-1),
European Committee for Standardization (CEN), Brussels, Belgium, 2004.

[5] GB 50936-2014, Technical Code for concrete Filled Steel Tubular Structures, Ministry of Housing and Urban-Rural Development of the People's Republic of China, Beijing, China, 2014, in Chinese.

[6] Y. Pan and S. Zhong, "The constitutive relationship of concrete filled steel tube under axial tension," Industrial Construction, pp. 30-37, 1990, in Chinese.

[7] L.-H. Han, S.-H. He, and F.-Y. Liao, "Performance and calculations of concrete filled steel tubes (CFST) under axial tension," Journal of Constructional Steel Research, vol. 67, no. 11, pp. 1699-1709, 2011.

[8] W. Li, L. Han, and T. Chan, "Performance of concrete-filled steel tubes subjected to eccentric tension," Journal of Structural Engineering, vol. 141, no. 12, Article ID 4015049, 2015.

[9] L. Han, Y. Hua, C. Hou, and Q. Wang, "Circular concretefilled steel tubes subjected to coupled tension and chloride corrosion," Journal of Structural Engineering, vol. 143, no. 10, Article ID 4017134, 2017.

[10] J. Chen, J. Wang, and W. L. Jin, "Concrete-filled steel tubes with reinforcing bars or angles under axial tension," Journal of Constructional Steel Research, vol. 133, pp. 374-382, 2017.

[11] J. Chen, J. Wang, and W. Li, "Experimental behaviour of reinforced concrete-filled steel tubes under eccentric tension," Journal of Constructional Steel Research, vol. 136, pp. 91-100, 2017.

[12] Y. Ye, W. Li, and Z. X. Guo, "Performance of concrete-filled stainless steel tubes subjected to tension: experimental investigation," Thin-Walled Structures, vol. 148, Article ID 106602, 2020.

[13] W. Li, L. H. Han, and T. M. Chan, "Tensile behaviour of concrete-filled double-skin steel tubular members," Journal of Constructional Steel Research, vol. 99, pp. 35-46, 2014.

[14] L. Han, Z. Wang, W. Xu, and Z. Tao, "Behavior of concreteencased CFST members under axial tension," Journal of Structural Engineering, vol. 142, no. 2, Article ID 4015149, 2016.

[15] F. Xu, J. Wang, J. Chen, and Y. H. Wang, "Load-transfer mechanism in angle-encased CFST members under axial tension," Engineering Structures, vol. 178, pp. 162-178, 2019.

[16] M. Zhou, J. S. Fan, M. X. Tao, and J. G. Nie, "Experimental study on the tensile behavior of square concrete-filled steel tubes," Journal of Constructional Steel Research, vol. 121, pp. 202-215, 2016.

[17] H. Zhu, Study on Mechanical Properties of Steel-Polyurethane Composite Pipe under Axial Loads, Jiangsu University of Science and Technology, Zhenjiang, China, 2011.

[18] Z. Hang, Study on Mechanical Properties of Polyurethane Composite Components of Circular Hollow sandwich Steel Tubes, Jiangsu University of Science and Technology, Zhenjiang, China, 2012.

[19] Y. Gao, F. Shao, P. Fan, Q. Xu, and X. Xie, "Effect of internal support on the tensile properties and fracture mode of 304 stainless steel thin-walled tubes," Materials, vol. 14, no. 1, 2021.

[20] Y. Gao, S. Fei, X. Qian et al., "Mechanical analysis of enhancement in tensile performance of thin-walled circular tubes by internal support," Advances in Mechanical Engineering, vol. 13, no. 7, Article ID 168781402110327, 2021. 
[21] ACI 318-02, Building Code Requirements for Reinforced concrete (ACI 318-02) and Commentary (ACI 318R-02), American Concrete Institute, Detroit, USA, 2002.

[22] BS5400, Steel, Concrete and Composite Bridges, Part 5, Code of Practice for Design of Composite Bridges, British Standards Institution, London, UK, 1979.

[23] M. Chen, "Incremental Constitutive Relation of Hardened Materials," Elastoplastic Mechanics, Science Press, Beijing, China, 2007, in Chinese.

[24] M. Zhou, L. Y. Xu, M. X. Tao, J. S. Fan, J. F. Hajjar, and J. G. Nie, "Experimental study on confining-strengthening, confining-stiffening, and fractal cracking of circular concrete filled steel tubes under axial tension," Engineering Structures, vol. 133, pp. 186-199, 2017. 